\title{
High glucose induces and activates Toll-like receptor 4 in endothelial cells of diabetic retinopathy
}

\author{
Lu Wang ${ }^{1,2}$, Jing Wang ${ }^{1}$, Jiazhu Fang ${ }^{1}$, Hongyan Zhou ${ }^{1}$, Xialin Liu ${ }^{1}$ and Shao Bo Su*
}

\begin{abstract}
Background: Hyperglycemia-induced inflammation causes the dysfunction of blood vessels, and Toll-like receptor 4 (TLR4) plays a key role in inflammation-induced angiogenesis. However, the impact of TLR4 on the pathogenesis of diabetic retinopathy (DR) is poorly understood. In this study, we examined the expression of TLR4 in retinal vascular endothelial cells of patients with DR and diabetic mice, and explored the role of TLR4 in mediating inflammatory responses by human microvascular endothelial cells (HMEC-1) under high-glucose condition.
\end{abstract}

Methods: The expression of TLR4 in retinal vascular endothelial cells of patients with proliferative diabetic retinopathy and diabetic mice induced by streptozotocin was examined using immunofluorescence. HMEC-1 cells were cultured and the expression of TLR4, MyD88 and Interleukin-1 $\beta$ (IL-1 $\beta$ ) was examined under high-glucose condition. Endothelial cells with TLR4 silencing and antagonist of TLR4 as well as endothelial cells from TLR4 deficient mice were used to study the effect of activated TLR4 on inflammation induced by high-glucose treatment.

Results: We observed that TLR4 was detected in CD31-labled human retinal vascular endothelia and its expression was markedly increased in fibrovascular membranes from DR patients and in retinal vascular endothelial cells of diabetic mice. The expression of TLR4, MyD88 and IL-1 $\beta$ was enhanced by high glucose in cultured HMEC-1 and the expression of TLR4 and IL-1 $\beta$ was inhibited by TLR4 siRNA knock-down and TLR4 antagonist. The expression of IL-1 $\beta$ by endothelial cells from TLR4 deficient mice under high glucose condition was decreased.

Conclusions: Our results revealed that hyperglycemia induced overexpression and activation of TLR4 in endothelial cells. This effect may lead to inflammatory responses contribute to the pathogenesis of diabetic retinopathy.

Keywords: Toll-like receptor 4, Diabetic retinopathy, Endothelium, Inflammation, Angiogenesis

\section{Background}

Diabetic retinopathy (DR) is a common microvascular complication of diabetes. It remains the major cause of blindness in developed countries. Multifactors have been shown to contribute to the initiation and progression of the disease in which inflammation is pivotal. Inflammation confers an increased risk for microvascular and macrovascular complications of diabetes. The proinflammatory phenotype in DR is characterized by elevated

\footnotetext{
*Correspondence: sushaobo7836@gmail.com

1 State Key Laboratory of Ophthalmology, Zhongshan Ophthalmic Center,

Sun Yat-sen University, Guangzhou 510060, China

Full list of author information is available at the end of the article
}

retinal cytokines, chemokines and adhesion molecules [1, 2].

Endothelial cells are key participants in retinal ischemic vasculopathies and their dysfunction is the initial event of microvascular disorder in DR [3]. Chronic inflammatory responses in retinal endothelia cause the production of inflammatory mediators, leading to increased vascular permeability, apoptosis of endothelial cells and neovascularization [3]. Hyperglycemia, one of the major risk factors for DR, could trigger inflammation and leads to vascular complications. Upon exposure to high glucose, endothelial cells show a series of inflammatory responses, such as reduced NO production [4], but enhanced NF- $\kappa \mathrm{B}$ activation [5], inflammatory gene expression [6] 
and leukocyte recruitment [7] by upregulated production of chemoattractants [8]. However, how hyperglycemia induces inflammation to contribute to DR remains unknown.

Toll-like receptors (TLRs) are pattern recognition receptors and recognize conserved pathogen-associated molecular patterns (PAMPs) and non-microbe molecules including endogenous ligands released during tissue damage and inflammation [9]. TLR activation triggers a signaling cascade leading to cytokine production and initiation of an adaptive immune response. TLR expression is increased in a plethora of inflammatory disorders, including diabetes [10]. Among TLRs, TLR4 recognizes lipopolysaccharide (LPS) from Gram-negative bacteria and endogenous ligands such as high-mobility group box 1 (HMGB1) and is expressed in multiple cells, such as endothelial cells and monocytes [11]. In retina, it has been reported that TLR4 was expressed in the diverse retinal cells, including retinal pigment epithelium, photoreceptors, astrocytes, microglia and retinal vascular endothelial cells [12].

TLR4 activates both the myeloid differentiation factor 88 (MyD88)-dependent pathway, which induces inflammatory cytokines, and TRIF-dependent pathway responsible for the induction of type I interferon. Several studies have shown that the expression of TLR4 is increased in atherosclerotic plaques of animal models of atherosclerosis. The lesion size, lipid content, and macrophage infiltration in atherosclerotic plaque were reduced in TLR4 knockout mice [13]. TLR4-mediated pathway also promotes dysfunction of mesangial cells that resulted in occluding of glomerular capillaries in Diabetic nephropathy [14]. Recent results suggest an association between Asp299Gly polymorphism in TLR4 gene and early onset of DR in DM2 patients. Toll-like receptor 4 polymorphisms was associated with a higher prevalence of retinopathy $[15,16]$. Hyperglycemia and free fatty acids (FFAs) synergistically promoted oxidative stress to aggravated the dysfunction of endothelia and insulin resistance, which are mediated by activated TLR4 [17, 18]. Additionally, the expression of downstream factors of TLR4 including MyD88 and NF- $\mathrm{kB}$, was significantly increased in cells exposed to high glucose $[17,19]$. This may lead to the secretion of inflammatory cytokines including IL-1 $\beta$ [20]. Studies showed that the level of IL-1 $\beta$ was significantly elevated in vitreous fluid of patients with proliferative diabetic retinopathy and in the retina fluid of DR rats [21]. Enhanced expression of TLR4 has been shown in monocytes of diabetic patients with microvascular complications [22]. Furthermore, the studies showed the involvement of TLR4 in other human diabetic complications like nephropathy, wound healing impairment. Lin et al. reported that Toll-like receptor 4 promoted tubular inflammation in diabetic nephropathy [23]. Down-regulation of TLR4 was shown in the impairment of wound healing in T2DM patients [24, 25]. TLR4 played an important role in the initiation and progression of cardiovascular pathologies [26]. Our previous study showed that TLR4 plays a critical role in inflammation-induced angiogenesis by promoting endothelial cell sprouting, proliferation and chemotaxis in a mouse model of alkali-induced corneal neovascularization [27]. We also found that TLR4 deficiency could protect mice from angiogenesis in oxygen-induced retinopathy model $[28,29]$.

Accumulating evidence implicated that TLR4-mediated inflammation was involved in diabetic vascular complication. However, the role of TLR4 in mediating the pathogenesis of DR by endothelial cells remains to be elucidated. In this study, we examined the role of TLR4dependent pathway in high glucose-induced inflammatory responses in retinal vascular endothelial cells. We demonstrate that high glucose challenge enhances the expression of TLR4 and the secretion of inflammatory factors by human endothelial cells. These results suggest an important role of hyperglycemia-induced expression and activation of TLR4 in diabetic retinopathy.

\section{Methods}

\section{Patients and tissue samples}

Five patients diagnosed as PDR were recruited from Zhongshan Ophthalmic Centre, Sun Yat-sen University, Guangzhou, China. Five normal human eye balls were from the Eye Bank of Zhongshan Ophthalmic Centre (Table 1). PDR patients underwent a series of ophthalmic examination, including the history of previous ocular treatments, slit-lamp biomicroscopy, gonioscopy ophthalmoscopy, fluorescein angiography, and fundus color photography. The severity of diabetic retinopathy was assessed based on the standardized fundus color photographs and on the fluorescein angiograms. The medical examination included fasting plasma concentrations of blood glucose and glycosylated hemoglobin. All patients received vitrectomy because of vitreous hemorrhage. Fibrovascular membranes from PDR patients were obtained during the surgery. The size are about $2.0 \mathrm{~mm} \times 2.0 \mathrm{~mm} \times 0.5 \mathrm{~mm}$. After immersed in PBS for $10 \mathrm{~s}$ three times, the tissues were embedded in OCT for section. This research was carried out in accordance with the principles of the Declaration of Helsinki as revised in 2000. Institutional Ethics Committee approval and informed consent from all patients were obtained.

\section{Animal studies}

C57BL/6 mice were purchased from Experimental Animal Centre of Sun Yat-sen University of Medical Science 
Table 1 Clinical characteristics for individual proliferative retinal membranes and human retina

\begin{tabular}{|c|c|c|c|c|}
\hline & $\begin{array}{l}\text { Age } \\
\text { (years) }\end{array}$ & Sex & Diagnosis & $\begin{array}{l}\text { Duration of } \\
\text { diabetes (years) }\end{array}$ \\
\hline \multicolumn{5}{|c|}{ Patient no. } \\
\hline 1 & 67 & M & $\begin{array}{l}\text { PDR epiretinal } \\
\text { membrane }\end{array}$ & 10 \\
\hline 2 & 48 & $F$ & $\begin{array}{l}\text { PDR epiretinal } \\
\text { membrane }\end{array}$ & 16 \\
\hline 3 & 69 & M & $\begin{array}{c}\text { PDR epiretinal } \\
\text { membrane }\end{array}$ & 8 \\
\hline 4 & 63 & M & $\begin{array}{l}\text { PDR epiretinal } \\
\text { membrane }\end{array}$ & 20 \\
\hline 5 & 68 & $F$ & $\begin{array}{l}\text { PDR epiretinal } \\
\text { membrane }\end{array}$ & 5 \\
\hline \multicolumn{5}{|c|}{ Control no. } \\
\hline 1 & 52 & M & Normal & $\mathrm{n} / \mathrm{a}$ \\
\hline 2 & 58 & $\mathrm{~F}$ & Normal & $\mathrm{n} / \mathrm{a}$ \\
\hline 3 & 51 & M & Normal & $\mathrm{n} / \mathrm{a}$ \\
\hline 4 & 60 & M & Normal & $\mathrm{n} / \mathrm{a}$ \\
\hline 5 & 61 & M & Normal & $\mathrm{n} / \mathrm{a}$ \\
\hline
\end{tabular}

$\mathrm{n} / \mathrm{a}$ indicates that there are no duration data for the control subjects

(Guangzhou, China). Care, use and the treatment of all animals were in strict agreement with the guidelines of the Association for Research in Vision and Ophthalmology Statement for the Use of Animals in Ophthalmic and Visual Research and approved by the institutional animal care and use committees in Zhongshan ophthalmic centre. To induce diabetes, 6 -week-old C57BL/6 mice were given five consecutive intraperitoneal injections of streptozotocin (STZ; $60 \mathrm{mg} / \mathrm{kg}$ body wt/day) (Sigma-Aldrich) or vehicle as control. Six and eight weeks after injection, mice were humanely killed and eyes were embedded in OCT for section.

\section{Immunofluorescence}

Dual-color immunofluorescence staining was performed on frozen sections of the fibrovascular membranes and mouse eye balls with a mouse anti-human or anti-mouse TLR4 monoclonal antibody (1:100 dilution; Santa Cruz Biotechnology, California, USA; 1:100 dilution; Abcam, Cambridge, MA, USA) and with rabbit anti-human/ mouse CD31 polyclonal IgG (1:100 dilution; Biosynthesis Biotechnology Co, Ltd, Beijing, China). The samples were then incubated with secondary goat anti-rabbit IgG antibody Alexa Fluor 555 and a goat anti-mouse IgG antibody Alexa Fluor 488 (1:500 dilution, Cell Signaling Technology, Boston, MA, USA) for $1 \mathrm{~h}$ at $37^{\circ} \mathrm{C}$ in the dark, followed by a 5-min incubation with Hoechst 33258 (1:1000 dilution; Sigma-Aldrich, St. Louis, Missouri, USA). Human retinal sections were examined at $400 \times$ with fluorescence microscope (Axioskop; Carl
Zeiss, Thornwood, NY, USA) and mouse retinal sections were examined at $400 \times$ by laser confocal microscope (LSCM 510 META; Oberkochen, Germany), maintaining identical settings. We further measured TLR4-immunofluorescence relative intensity in each optical slice along lines around inner layer of blood vessels in human retina samples and transecting inner layer of mouse retina by Image-Pro Plus 6.0 (Media Cybernetics, Silver Spring, Maryland, USA). Image processing was performed with Adobe Photoshop CS 3.0 (Adobe Systems, San Jose, CA, USA).

\section{Cell culture}

HMEC-1 human microvascular endothelial cell line was obtained from American Type Culture Collection (Manassas, VA, USA). HMEC-1 cells were cultured in human endothelial-SFM $(5.5 \mathrm{mmol} / \mathrm{L}$ glucose, Invitrogen, Carlsbad, CA, USA). Mouse retinal endothelial cells (MRECs) of wild type mice and TLR4 knockout mice were purchased from PriCells (Wuhan, China) and were cultured in endothelial cell complete medium (MED0002 + SUP0002, PriCells) according to the manufacturer's instructions. Only cells between passages 3 and 8 were used in the study. The glucose was purchased from Sigma-Aldrich, St. Louis, MO, USA. The cells were treated with $5.5 \mathrm{mmol} / \mathrm{l}$ normal glucose or with 15 and $25 \mathrm{mmol} / \mathrm{l}$ glucose for indicated times in sustained condition. The cells were also pretreated with TLR4 antagonist Rhodobacter sphaeroides LPS (LPS-RS) (Invivogen, San Diego, CA, USA) or TLR4 siRNA (Santa Cruz Biotechnology, California, USA) according to the instruction of

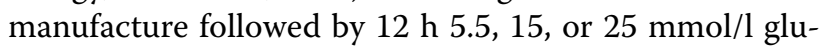
cose treatment. Cell supernatants, lysates and RNA were collected for further experiments.

\section{RNA extraction and real-time quantitative RT-PCR}

HMEC-1 cells or MRECs were cultured in $30-\mathrm{mm}$ tissue culture dishes. After treatment with glucose, total RNA was extracted using Trizol reagent (Invitrogen, Carlsbad, CA, USA) and the cDNA was prepared by reverse transcription according to the manufacturer's protocol. Real-time PCR was performed on an Applied Biosystems StepOne Real-Time PCR System using the comparative threshold cycle $(\mathrm{CT})$ quantification method. Each reaction contained $12.5 \mu \mathrm{l}$ of $2 \times$ SYBR green Master Mix, $300 \mathrm{nM}$ oligonucleotide primers synthesized by Invitrogen Biotechnology Co. Ltd, (Shanghai, China), $10 \mu \mathrm{l}$ of 1 in 10 dilution of the cDNA and water, to a total of $25 \mu$. The thermal cycling conditions included an initial denaturation at $95{ }^{\circ} \mathrm{C}$ for $10 \mathrm{~min}, 40$ cycles at $95{ }^{\circ} \mathrm{C}$ for $30 \mathrm{~s}, 60{ }^{\circ} \mathrm{C}$ for $1 \mathrm{~min}$, and $72{ }^{\circ} \mathrm{C}$ for $1 \mathrm{~min}$. The mRNA expression in each sample was determined after correction with the expression of human GAPDH or mouse 
GAPDH. Each measurement of a sample was conducted in triplicate. The following primers were used: human GAPDH (70 bp): forward: CCACATCGCTCAGACACCAT; reverse: CCAGGCGCCCAATACG; human TLR4 (138 bp): forward: ATGAAATGAGTTGCAGCAGA; reverse: AGCCATCGTTGTCTCCCTAA; human IL-1 $\beta$ (133 bp): forward: TCCAGGGACAGGATATGGAG; reverse: TCTTTCAACACGCAGGACAG; human VEGF (120 bp): forward: TCCAGGAGTACCCTGATGAG; reverse: ATTCACATTTGTGTGCTGT; human bFGF (184 bp): forward: GAGGAGTTGTGTCTATCAAAG; reverse: GTTCGTTTCAGTGCCACATACC; mouse GAPDH (93 bp): forward: TGAGCAAGAGAGGCCCTATC, reverse: AGGCCCCTCCTGTTATTATG; mouse IL-1 $\beta$ (105 bp): forward: TCCAGGATGAGGACATGAGCAC, reverse: GAACGTCACACACCAGCAGGTTA. All mRNA values were normalized against the levels of human or mouse GAPDH mRNA. The normalized values of treatment groups are expressed as the fold increase over the untreated control cells in y axis.

\section{Western blotting}

HMEC-1 cells treated with glucose were collected and lysed with lysis buffer containing RIPA and phenylmethylsulfonyl fluoride (PMSF). Protein concentration was determined by the Bradford-Lowry method and the samples were stored at $-80{ }^{\circ} \mathrm{C}$ until used for immunoblot analysis. Protein samples $(30 \mu \mathrm{g})$ were loaded onto SDS-PAGE gels and then were transferred to a PVDF membrane (Immobilon-P; Millipore, Bedford, MA, USA). After being blocked with $5 \%$ nonfat milk for $1 \mathrm{~h}$, the membrane were incubated with the following primary antibodies at $4{ }^{\circ} \mathrm{C}$ overnight: polyclonal rabbit antihuman TLR4 (1:500; Boster Wuhan, China), polyclonal rabbit anti-human MyD88 (1:100; Boster Wuhan, China) and monoclonal mouse anti- $\beta$-actin (1:100; Boster, Wuhan, China). Protein bands were visualized by incubation with anti-mouse secondary antibody or anti-rabbit secondary antibody (1:3000; BOSTER, Wuhan, China) and chemiluminescence substrates (ECL Plus; TIANGEN, Beijing, China).

\section{Flow cytometry}

HMEC-1 cells were cultured in 24-well plates for at least $24 \mathrm{~h}$, then were stimulated with $15 \mathrm{mmol} / \mathrm{l}$ glucose for another $24 \mathrm{~h}$. The cells were then blocked by $5 \%$ BSA PBS for $30 \mathrm{~min}$, and were incubated with FITC labeled anti-TLR4 antibody (eBioscience Inc., San Diego, CA, USA) for $1 \mathrm{~h}$ at $4{ }^{\circ} \mathrm{C}$. After the incubation, cells were scraped and suspended in $500 \mu \mathrm{l}$ buffer. The intensity of fluorescence was measured using a FACSCalibur and CellQuest software (BD PharMingen).

\section{Enzyme-linked immunosorbent assays (ELISA)}

HMEC1 cells with/without siRNA silence or MRECs of wild type or TLR4 knockout mice were stimulated with glucose. Culture supernatant was harvested, centrifuged to remove cellular debris, and then stored at $-80{ }^{\circ} \mathrm{C}$ until use. The concentration of IL- $1 \beta$ in the supernatants was measured by human IL-1 $\beta$ ELISA (Boster Corporation, Wuhan, China) or mouse IL-1 $\beta$ ELISA (R\&D Systems, Minneapolis, MN, USA) according to manufacturer's instructions.

\section{Reproducibility and statistical analysis}

All experiments were performed at least three times. Results were highly reproducible. Representative results were shown in figures. Results are expressed as the mean \pm SE. Data were analyzed by ANOVA with $\mathrm{S}-\mathrm{N}-\mathrm{K}$ post hoc analyses. All statistical analyses were performed using SPSS20.0 Software. $P<0.05$ was considered as statistically significant.

\section{Results \\ The expression of TLR4 in premembrane of diabetic retinopathy patients}

Our previous study showed that TLR4 played a critical role in inflammation-induced angiogenesis in a mouse model. In this study, we at first examined the expression of TLR4 in the premembranes of patients with diabetic retinopathy. The premembranes of five diabetic retinopathy patients and retinas of five normal human eye balls were examined with immunofluorescence staining. The expression of TLR4 was detected in the retina from normal human eyes (Fig. 1a, Control 1-5) and fibrovascular membranes removed from the eyes of patients with PDR (Fig. 1a, PDR 1-5). Positive staining of CD31, an endothelial marker, was present in both tissues. Colocalization of TLR4 and CD31 was observed in vessel walls. TLR4 expression was significant higher in PDR fibrovascular membranes than in normal retinal vasculatures (Fig. 1b). These data suggest that TLR4 expression is increased in the fibrovasculature and may play a role in the dysfunction of vascular endothelial cells in DR.

\section{The expression of TLR4 in retinal endothelial cells in STZ-induced diabetic mice}

STZ-induced diabetes in mice is a commonly used model to study nonproliferative DR. We examined the expression of TLR4 in mice 6 and 8 weeks after STZ injection (Fig. 2a, c). Colocalization of TLR4 and CD31 was observed in vessel walls. We found that in the diabetic retina, TLR4 level was significantly increased at 6 and 8 weeks after STZ injection compared to control mice (Fig. 2b, d). 


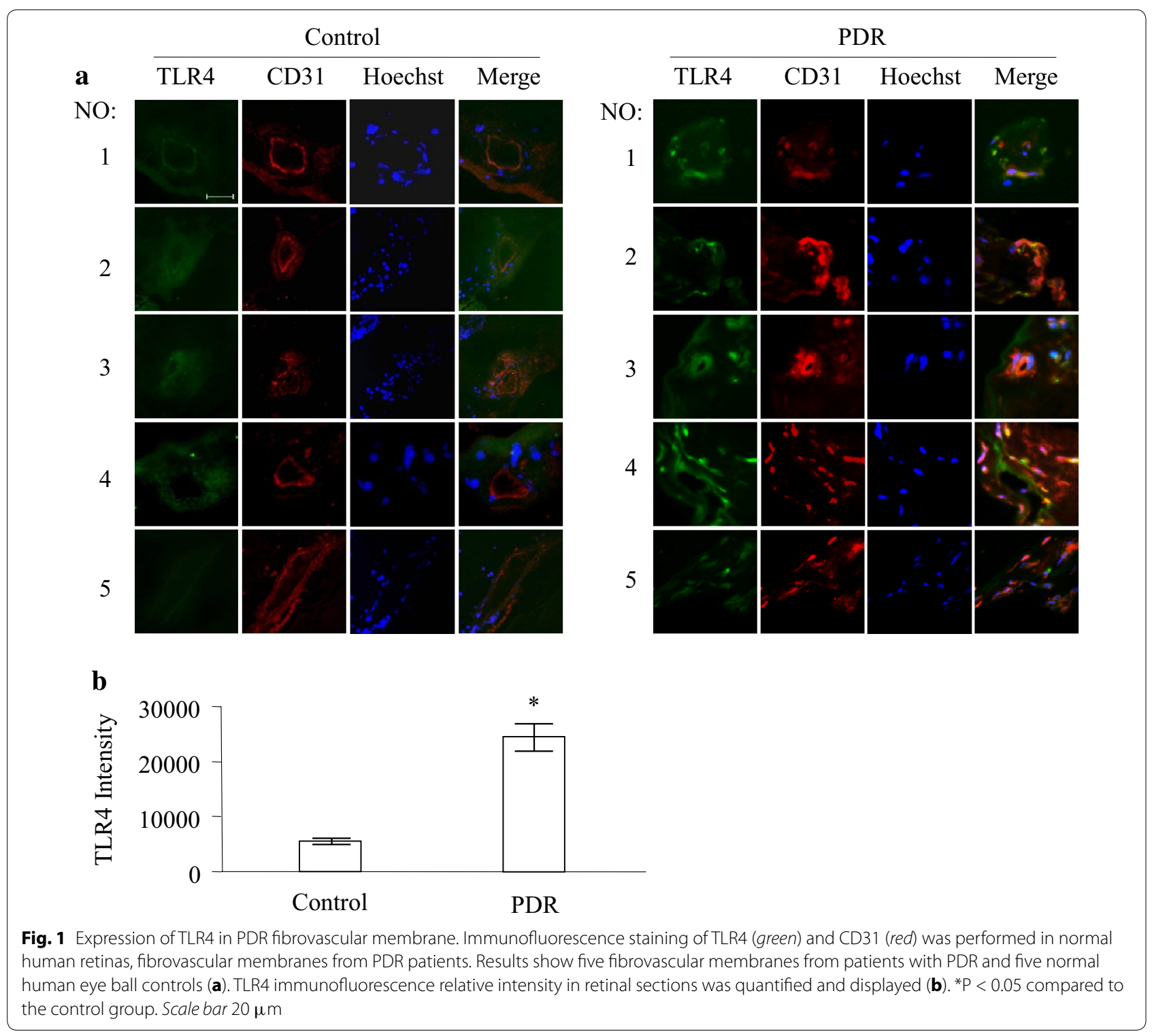

High glucose culture induced the expression of TLR4 by HMEC- 1 cells

We then used HMEC-1 cells as a model to examine microvascular endothelial cell response to increased concentration of glucose. HMEC-1 cells were exposed to 5.5 (normal), 15 and $25 \mathrm{mmol} / \mathrm{l}$ glucose for variable time points. Increased expression of TLR4 mRNA was observed after glucose exposure and the highest level of TLR4 expression was induced by $25 \mathrm{mmol} / \mathrm{l}$ glucose (Fig. 3a). The increase in TLR4 expression by HMEC-1 cells in response to glucose was time dependent and reached the maximum at $6 \mathrm{~h}$ after treatment (Fig. 3b). Western blotting (Fig. 3c) showed a markedly increase in TLR4 expression at 12 and $24 \mathrm{~h}$ after high glucose challenge. Analysis of flow cytometry showed similar effect when glucose was used at 15 and $25 \mathrm{mmol} / \mathrm{l}$ (Fig. 3d).

\section{Induction of MyD88 expression in HMEC-1 cells by high} glucose

Activation of MyD88 is a key step in the TLR4 pathway that culminates in NF- $\kappa$ B activation and inflammatory cytokine expression. We examined the effect of high glucose on the expression of MyD88 by HMEC-1 cells using Western blotting. We observed that high glucose increased the expression of MyD88 by HMEC-1 cells at 15 and $25 \mathrm{mmol} / \mathrm{l}$ for $12 \mathrm{~h}$ (Fig. 4a). These findings indicate that increased TLR4 expression under high glucose 


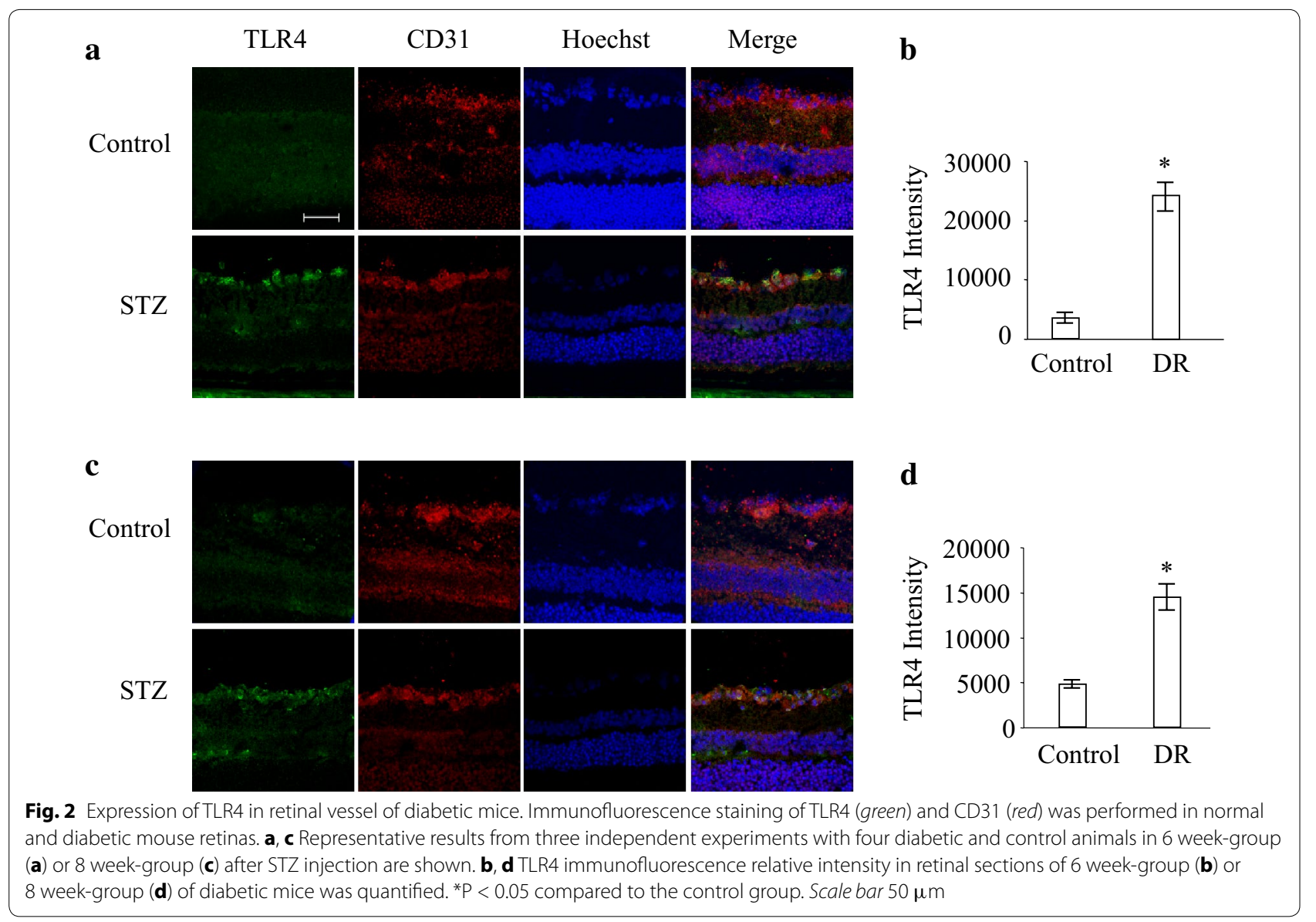

exposure induces the expression of MyD88, which may activate inflammatory cascade.

\section{Increased inflammatory cytokine production by HMEC-1 cells in response to high glucose}

To investigate the inflammatory response of TLR4, we determined the expression of inflammatory cytokine IL-1 $\beta$ as well as VEGF and bFGF by HMEC- 1 cells under high glucose condition. The level of IL-1 $\beta$ mRNA after 15 and $25 \mathrm{mmol} / \mathrm{l}$ glucose treatment was significantly increased compared with treatment with $5.5 \mathrm{mmol} / \mathrm{l}$ glucose (Fig. 4b) $(p<0.05)$. Kinetic study showed treatment with $15 \mathrm{mmol} / \mathrm{l}$ glucose significantly increased IL-1 $\beta$ mRNA at 3, 6, 12 and $24 \mathrm{~h}$ (Fig. 4c). We then measured IL-1 $\beta$ protein in the cultural supernatant of glucose-treated HMEC-1 cells. IL-1 $\beta$ level was significantly increased at $6,12,24 \mathrm{~h}$ and persisted under high glucose condition (15 mmol/l) (Fig. 4d). Similarly, stimulation of HMEC-1 cells by $15 \mathrm{mmol} / \mathrm{l}$ glucose enhanced the expression of VEGF and bFGF (Additional file 1: Figure S1). Therefore, high glucose elevates the secretion of inflammatory and proangiogenic cytokines via activation of TLR4 pathway.
Inflammatory response activated by high glucose via TLR4 in HMEC-1 cells

siRNA was used to confirm the role of TLR4 in high glucose-induced inflammatory response. TLR4 expression in HMEC-1 cells was significantly decreased after siRNA transfection (Fig. 5a). This resulted in significant decrease in IL-1 $\beta$ level at $15 \mathrm{mmol} / \mathrm{l}$ glucose treatment (Fig. 5b). Scrambled siRNA had no significant effect on IL-1 $\beta$ expression by HMEC-1 cells (Fig. 5b). We also tested the effects of a TLR4 antagonist, Rhodobacter sphaeroides LPS (LPS-RS), on high glucose-induced inflammatory response in HMEC-1 cells. LPS-RS reduced the production of IL- $1 \beta$ by HMEC- 1 cells at $15 \mathrm{mmol} / \mathrm{l}$ glucose treatment (Fig. 5c). These findings confirmed that the effect of high glucose on the production of IL- $1 \beta$ by HMEC- 1 cells was TLR4-dependent.

\section{Reduction of high glucose-induced cytokine production by MRECs from TLR4 deficient mice}

Next, we determined the expression of IL- $1 \beta$ under high glucose condition by MRECs from TLR4 deficient mice. Real-time PCR showed that the expression of IL-1 $\beta$ by WT mouse MRECs under $15 \mathrm{mmol} / \mathrm{l}$ glucose was 


\section{a}

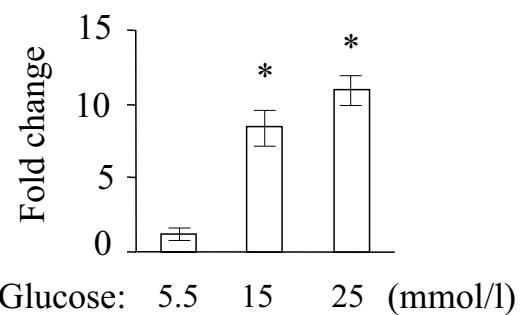

c

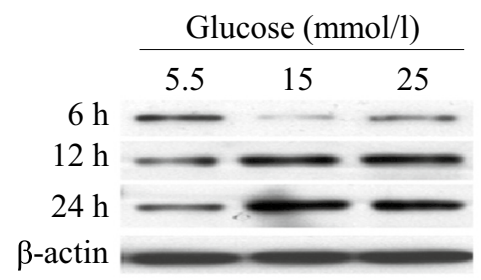

$\mathbf{b}$

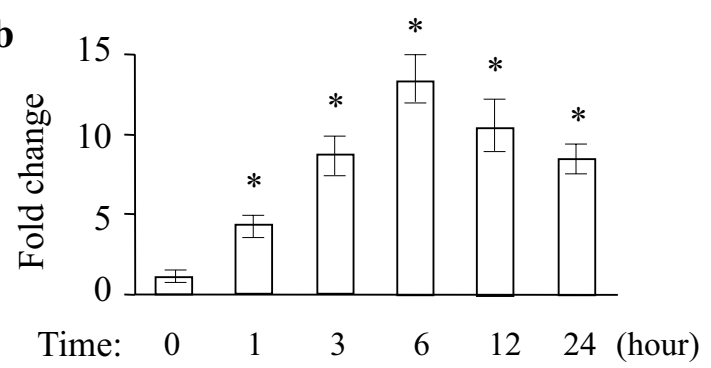

d

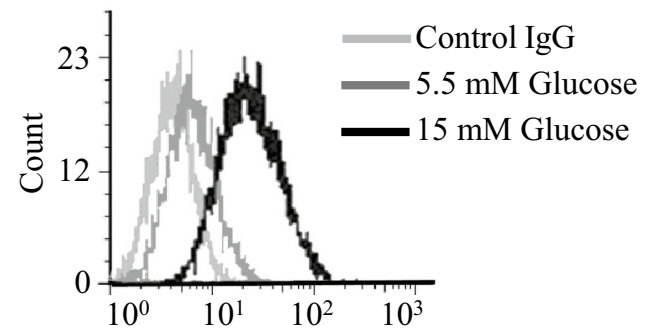

Fig. 3 Expression of TLR4 in HMEC-1 cells subjected to high glucose. a HMEC-1 cells were stimulated with glucose at the doses of 15 and $25 \mathrm{mmol} / \mathrm{l}$ for $6 \mathrm{~h}$. The mRNA for TLR4 was detected by quantitative RT-PCR and normalized to GAPDH. Asterisk indicates $P<0.05$ compared to $5.5 \mathrm{mmol} / \mathrm{l}$ glucose. b The cells were stimulated with $15 \mathrm{mmol} / \mathrm{l}$ glucose for $0,1,3,6,12$ and $24 \mathrm{~h}$. The mRNA of TLR4 was detected by quantitative RT-PCR and normalized to GAPDH and expressed as the mean \pm SE. ${ }^{*} P<0.05$ compared to the 0 h group. c HMEC-1 cells were treated with $5.5,15$ and $25 \mathrm{mmol} / \mathrm{l}$ glucose for 6,12 and $24 \mathrm{~h}$ and western blot was performed. $\beta$-actin was used as a control. d TLR4 expression on HMEC- 1 cells challenged with $15 \mathrm{mmol} / \mathrm{l}$ glucose for $24 \mathrm{~h}$ assessed by flow cytometry

$\mathbf{a}$

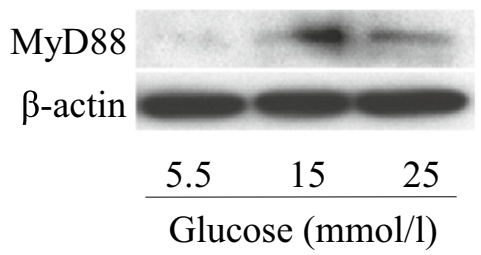

b

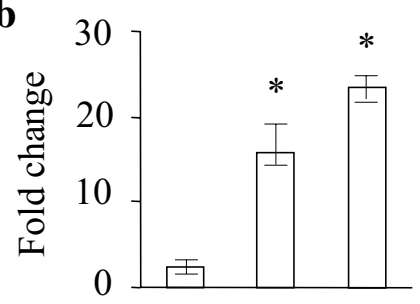

Glucose: $5.5 \quad 15 \quad 25(\mathrm{mmol} / \mathrm{l})$

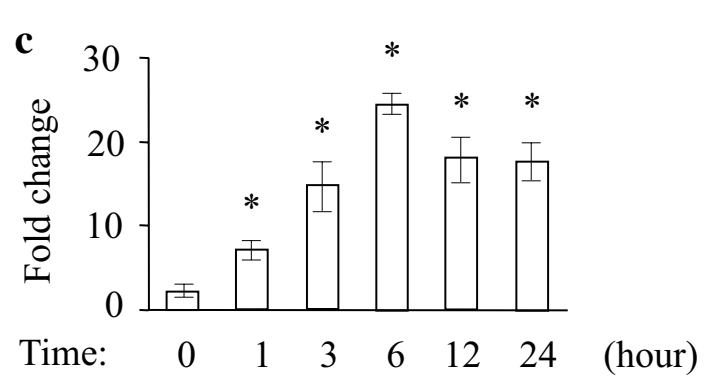

d

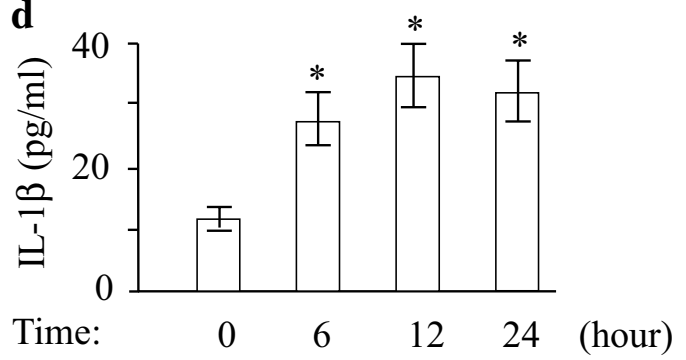

Fig. 4 Activation of MyD88 and cytokine expression in HMEC-1 cells under high glucose condition. a Western blotting was performed for MyD88 expression in the HMEC-1 cells after exposure to 15 and $25 \mathrm{mmol} / \mathrm{l}$ glucose for $12 \mathrm{~h}$. $\beta$-actin was used as a control. b Cells were treated with 15 and $25 \mathrm{mmol} / \mathrm{I}$ glucose for $6 \mathrm{~h}$. The mRNA for IL-1 $\beta$ was detected by quantitative RT-PCR and normalized to GAPDH. Asterisk indicates $P<0.05$ compared to $5.5 \mathrm{mmol} / \mathrm{l}$ glucose. $\mathbf{c}$ The cells were stimulated with $15 \mathrm{mmol} / \mathrm{l}$ glucose for $0,1,3,6,12$ and $24 \mathrm{~h}$. The mRNA of IL-1 $\beta$ was detected by quantitative RT-PCR and normalized to GAPDH to the $0 \mathrm{~h}$ group and expressed as the mean $\pm \mathrm{SE}$. ${ }^{*} P<0.05$ compared to the $0 \mathrm{~h}$ group. $\mathbf{d} \mathrm{IL}-1 \beta$ protein in the supernatants of HMEC-1 cells after high-glucose treatment for indicated time points measured using ELISA. Asterisk indicates $P<0.05$ compared to $5.5 \mathrm{mmol} / \mathrm{l}$ glucose 
$\mathbf{a}$

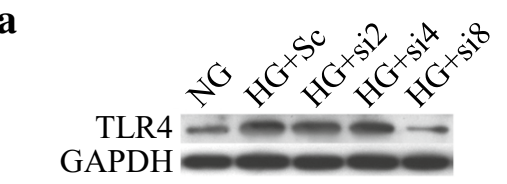

b

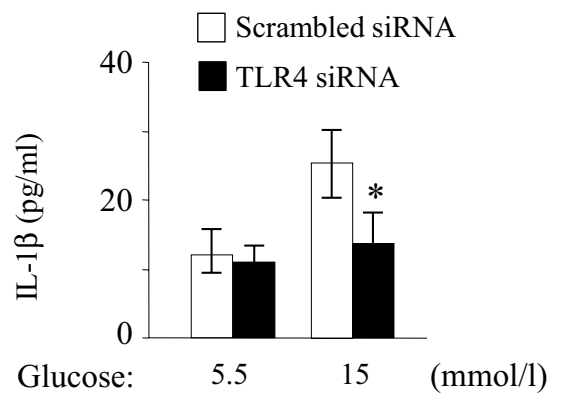

c

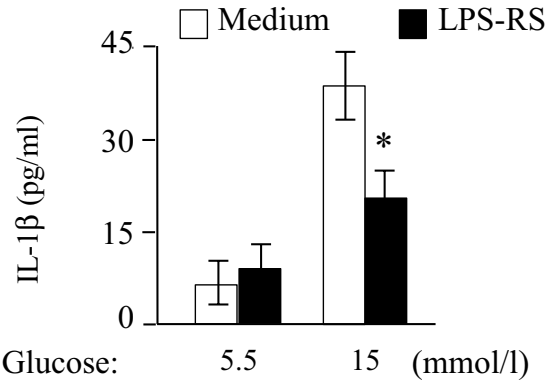

Fig. 5 Inhibition of TLR4 reduces high glucose-induced production of IL-1 $\beta$ by HMEC -1 cells. a Western blot analysis of TLR4 expression by HMEC-1 cells under high glucose condition after siRNA treatment. NG normal glucose, $H G$ high glucose, Sc scrambled control siRNA, si2 TLR4 siRNA 0.2 pmol/l, si4 TLR4 siRNA 0.4 pmol/l, si8 TLR4 siRNA 0.8 pmol/l. b $\mid L-1 \beta$ concentration in supernatants of HMEC-1 cells after high-glucose treatment in the presence of TLR4 siRNA (0.8 pmol/l) was measured using ELISA. Asterisk indicates $P<0.05$ compared to $5.5 \mathrm{mmol} / \mathrm{l}$ glucose. $\mathbf{c} \| \mathrm{L}-1 \beta$ level in supernatants of HMEC-1 cells in the presence of TLR4 antagonist LPS-RS $(1 \mu \mathrm{g} / \mathrm{ml})$ after high-glucose treatment was measured using ELISA. Asterisk indicates $P<0.05$ compared to scrambled control RNA

increased. However, the expression of IL- $1 \beta$ in MRECs from TLR4 deficient mice was significantly reduced (Fig. 6a) $(p<0.05)$. Similarly, the production of IL- $1 \beta$ protein by MRECs from TLR4 ${ }^{-1-}$ mice was also significantly reduced in comparison with WT mouse cells (Fig. 6b) $(p<0.05)$. These data confirm that TLR4 plays a critical role in high glucose-induced inflammatory responses in endothelial cells.

\section{Discussion}

Diabetic retinopathy is a common vascular complication and appears to involve inflammatory responses [30]. Hyperglycemia induces inflammation, affects the
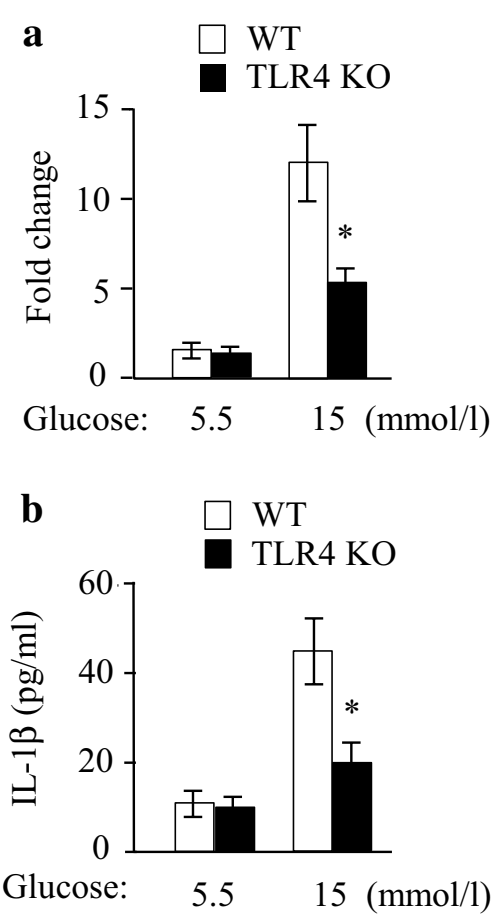

Fig. 6 The expression of IL-1 $\beta$ by MRECs from TLR4 deficient mice under high glucose condition. MRECSs of wild type (WT) mice and TLR4 knockout (TLR4 KO) mice were cultured with 5.5 and $15 \mathrm{mmol} / \mathrm{l}$ glucose for $6 \mathrm{~h}(\mathbf{a})$ and $24 \mathrm{~h}(\mathbf{b})$. a The mRNA level of IL-1 $\beta$ was determined by real time PCR. Asterisk indicates $P<0.05$ compared to WT mice. $\mathbf{b} \| \mathrm{L}-1 \beta$ protein concentration in the supernatants of MRECS after high-glucose treatment for $24 \mathrm{~h}$ was measured using ELISA.

Asterisk indicates $P<0.05$ compared to WT mice

production of extracellular matrix and procoagulant proteins, causes apoptosis and inhibits the proliferation of endothelial cells. These events resulted in endothelial dysfunction in diabetic retinopathy [31].

Abnormalities in glucose concentration have been reported to elevate and activate TLR4 to promote the secretion of inflammatory cytokines in mouse mesangial cells and contribute to diabetic nephropathy [14,23]. The expression and function of TLR4 are elevated in monocytes of diabetic patients [17, 32]. Genetic deficiency of TLR4 is associated with significant reduction of aortic plaque and lower triglyceride accumulation in the heart in early stages of diabetes $[13,33]$. In addition, TLR4 gene polymorphism was found to be associated with diabetic retinopathy [15]. Thus, our findings of increased TLR4 in endothelial cells after high glucose exposure provide the evidence for the role of TLR4 in diabetic retinopathy.

Hyperglycemia, particularly the fluctuation of glucose levels, causes a significant oxidative stress, decreasing the expression of endothelial nitric oxide synthase and impairing NO metabolism [34]. Fluctuating 
hyperglycemia induces an increased production of collagen. Furthermore, fluctuations of glycemia increase endothelial cell apoptosis, endothelial expression of adhesion molecules, and vascular smooth muscle cell proliferation [35]. Thus, glucose fluctuations appear to be more deleterious to vascular cell integrity than constant high glucose concentrations.

Oxidative stress plays a critical role in mediating the upregulation of TLR4 under hyperglycemic conditions. It is reported that hyperglycemia induces TLR4 expression in hyperglycemic human retinal endothelial cells. It also increases both MyD88 and non-MyD88 pathways, nuclear factor- $\mathrm{KB}$ (NF- $\mathrm{KB}$ ), biomediators, and monocyte adhesion. Antioxidant treatment reduced TLR4 expression and downstream inflammatory markers [36]. The articles by Mudaliar et al. [37] and Lu et al. [38] showed that TLR4 play an important role in mediating inflammatory pathways in endothelial cells exposed to high glucose. Therefore, strategies to block TLR4 signaling pathways pose a promising avenue to alleviate diabeticinduced vascular complications.

Hyperglycemia-induced TLR4 expression in human monocytes is associated with increased NAPDH oxidase activity triggered by PKC [17]. High glucose increased PKC- $\delta$ activity that mediates a wide range of cellular function including increased translocation of NF- $\mathrm{KB}$ [39]. Additionally, PKC- $\delta$ stimulates p $47 \mathrm{Phox}$, a NADPH oxidase cytosolic subunit, which in turn stimulates the NAPDH oxidase activity to generate ROS critical for TLR4-mediated activation of NF-кB. Furthermore, high glucose was found to enhance the apoptosis of endothelial cells by activation of PKC and NAPDH [17].

\section{Conclusion}

Our study demonstrated that hyperglycemia enhances the expression of TLR4 and activates TLR4 in human endothelial cells that may play an important role in diabetic retinopathy. Thus, targeting TLR4 signaling pathway may be a novel therapeutic approach to vasculature-related disorders.

\section{Additional file}

Additional file 1: Figure S1. HMEC-1 cells were cultured with glucose at the doses of 5.5 and $15 \mathrm{mmol} / \mathrm{l}$ for $6 \mathrm{~h}$. The mRNA for VEGF and bFGF was detected by quantitative RT-PCR and normalized to GAPDH. * indicates $P<0.05$ compared to $5.5 \mathrm{mmol} / \mathrm{l}$ glucose.

\section{Abbreviations}

DR: diabetic retinopathy; ELISA: enzyme-linked immunosorbent assays; HMEC1: human microvascular endothelial cells; IL: interleukin; LPS: lipopolysaccharide; MRECs: mouse retinal endothelial cells; LPS-RS: Rhodobacter sphaeroides lipopolysaccharide; PAMPs: pathogen-associated molecular patterns; STZ: streptozotocin; TLR4: toll-like receptor 4 .

\section{Authors' contributions}

LW, JW, JF, HZ, XL and SBS were deeply involved in the conception and design of the study. LW, XL and SBS were responsible for the analyses of the data and drafted the manuscript. All authors read and approved the final manuscript.

\section{Author details}

'State Key Laboratory of Ophthalmology, Zhongshan Ophthalmic Center, Sun Yat-sen University, Guangzhou 510060, China. ${ }^{2}$ Guangdong Province Hospital of Traditional Chinese Medicine, Guangzhou 510120, China.

\section{Acknowledgements}

We are grateful to Dr. Ji Ming Wang, National Cancer Institute, National Institutes of Health for his helpful critique of the manuscript. This project was supported in part by the grants from the National Natural Science Foundation of China (31471122).

\section{Competing interests}

The authors declare that they have no competing interests.

Received: 26 June 2015 Accepted: 6 October 2015

Published online: 13 October 2015

\section{References}

1. Zheng L, Kern TS. Role of nitric oxide, superoxide, peroxynitrite and PARP in diabetic retinopathy. Front Biosci. 2009;14:3974-87.

2. Kocak N, Alacacioglu I, Kaynak S, et al. Comparison of vitreous and plasma levels of vascular endothelial growth factor, interleukin- 6 and hepatocyte growth factor in diabetic and non-diabetic retinal detachment cases. Ann Ophthalmol (Skokie). 2010;42 Spec No: 10-4.

3. Bharadwaj AS, Appukuttan B, Wilmarth PA, et al. Role of the retinal vascular endothelial cell in ocular disease. Prog Retin Eye Res. 2013;32:102-80.

4. Du XL, Edelstein D, Dimmeler S, et al. Hyperglycemia inhibits endothelial nitric oxide synthase activity by posttranslational modification at the Akt site. J Clin Invest. 2001;108:1341-8.

5. Luppi P, Cifarelli V, Tse H, et al. Human C-peptide antagonises high glucose-induced endothelial dysfunction through the nuclear factorkappaB pathway. Diabetologia. 2008;51:1534-43.

6. Piga R, Naito Y, Kokura S, et al. Short-term high glucose exposure induces monocyte-endothelial cells adhesion and transmigration by increasing VCAM-1 and MCP-1 expression in human aortic endothelial cells. Atherosclerosis. 2007;193:328-34.

7. Esposito C, Fasoli G, Plati AR, et al. Long-term exposure to high glucose up-regulates VCAM-induced endothelial cell adhesiveness to PBMC. Kidney Int. 2001;59:1842-9.

8. Piconi L, Quagliaro L, Da Ros R, et al. Intermittent high glucose enhances ICAM-1, VCAM-1, E-selectin and interleukin-6 expression in human umbilical endothelial cells in culture: the role of poly(ADP-ribose) polymerase. J Thromb Haemost. 2004:2:1453-9.

9. Kawai T, Akira S. The role of pattern-recognition receptors in innate immunity: update on Toll-like receptors. Nat Immunol. 2010;11:373-84.

10. Devaraj S, Dasu MR, Rockwood J, et al. Increased toll-like receptor (TLR) 2 and TLR4 expression in monocytes from patients with type 1 diabetes: further evidence of a proinflammatory state. J Clin Endocrinol Metab. 2008;93:578-83.

11. Yang $\mathrm{H}$, Tracey KJ. Targeting HMGB1 in inflammation. Biochim Biophys Acta. 2010;1799:149-56.

12. Ko MK, Saraswathy S, Parikh JG, et al. The role of TLR4 activation in photoreceptor mitochondrial oxidative stress. Invest Ophthalmol Vis Sci. 2011;52:5824-35.

13. Michelsen KS, Wong MH, Shah PK, et al. Lack of Toll-like receptor 4 or myeloid differentiation factor 88 reduces atherosclerosis and alters plaque phenotype in mice deficient in apolipoprotein E. Proc Natl Acad Sci USA. 2004;101:10679-84.

14. Kaur H, Chien A, Jialal I. Hyperglycemia induces Toll like receptor 4 expression and activity in mouse mesangial cells: relevance to diabetic nephropathy. Am J Physiol Renal Physiol. 2012;303:F1145-50. 
15. Buraczynska M, Baranowicz-Gaszczyk I, Tarach J, et al. Toll-like receptor 4 gene polymorphism and early onset of diabetic retinopathy in patients with type 2 diabetes. Hum Immunol. 2009;70:121-4.

16. Singh K, Kant S, Singh VK, et al. Toll-like receptor 4 polymorphisms and their haplotypes modulate the risk of developing diabetic retinopathy in type 2 diabetes patients. Mol Vis. 2014;20:704-13.

17. Dasu MR, Devaraj S, Zhao L, et al. High glucose induces toll-like receptor expression in human monocytes: mechanism of activation. Diabetes. 2008;57:3090-8

18. Pal D, Dasgupta $S$, Kundu $R$, et al. Fetuin-A acts as an endogenous ligand of TLR4 to promote lipid-induced insulin resistance. Nat Med. 2012;18:1279-85.

19. Quagliaro L, Piconi L, Assaloni R, et al. Intermittent high glucose enhances apoptosis related to oxidative stress in human umbilical vein endothelial cells: the role of protein kinase $\mathrm{C}$ and $\mathrm{NAD}(\mathrm{P}) \mathrm{H}$-oxidase activation. Diabetes. 2003;52:2795-804

20. Dasu MR, Jialal I. Free fatty acids in the presence of high glucose amplify monocyte inflammation via Toll-like receptors. Am J Physiol Endocrinol Metab. 2011;300:E145-54

21. Wang YL, Wang K, Yu SJ, et al. Association of the TLR4 signaling pathway in the retina of streptozotocin-induced diabetic rats. Graefe's Arch Clin Exper Ophthalmol Albrecht von Graefes Archiv fur klinische und experimentelle Ophthalmologie 2015;253:389-98.

22. Devaraj S, Jialal I, Yun JM, et al. Demonstration of increased toll-like receptor 2 and toll-like receptor 4 expression in monocytes of type 1 diabetes mellitus patients with microvascular complications. Metabolism. 2011;60:256-9.

23. Lin $\mathrm{M}$, Yiu WH, Wu HJ, et al. Toll-like receptor 4 promotes tubular inflammation in diabetic nephropathy. J Am Soc Nephrol. 2012;23:86-102.

24. Singh K, Singh VK, Agrawal NK, et al. Association of Toll-like receptor 4 polymorphisms with diabetic foot ulcers and application of artificial neural network in DFU risk assessment in type 2 diabetes patients. Biomed Res Int. 2013;2013:318686

25. Kanhaiya AN, Gupta SK, Singh Kiran. Differential expression of toll like receptor 4 in type 2 diabetic patients with impaired wound healing. J Diabetes Metab. 2013;4:260.

26. de Kleijn D, Pasterkamp G. Toll-like receptors in cardiovascular diseases. Cardiovasc Res. 2003;60:58-67.
27. Lin $Q$, Yang XP, Fang D, et al. High-mobility group box-1 mediates toll-like receptor 4-dependent angiogenesis. Arterioscler Thromb Vasc Biol. 2011;31:1024-32.

28. He C, Sun Y, Ren $X$, et al. Angiogenesis mediated by toll-like receptor 4 in ischemic neural tissue. Arterioscler Thromb Vasc Biol. 2013;33:330-8.

29. Yang $S, X u L$, Yang $T$, et al. High-mobility group box-1 and its role in angiogenesis. J Leukoc Biol. 2014;95:563-74.

30. Tang J, Kern TS. Inflammation in diabetic retinopathy. Prog Retin Eye Res. 2011;30:343-58.

31. Hsueh WA, Anderson PW. Hypertension, the endothelial cell, and the vascular complications of diabetes mellitus. Hypertension. 1992;20:253-63.

32. Jialal I, Huet BA, Kaur H, et al. Increased toll-like receptor activity in patients with metabolic syndrome. Diabetes Care. 2012;35:900-4.

33. Dong B, Qi D, Yang $L$, et al. TLR4 regulates cardiac lipid accumulation and diabetic heart disease in the nonobese diabetic mouse model of type 1 diabetes. Am J Physiol Heart Circ Physiol. 2012;303:H732-42.

34. Chen $X$, Feng $L$, Jin H. Constant or fluctuating hyperglycemias increases cytomembrane stiffness of human umbilical vein endothelial cells in culture: roles of cytoskeletal rearrangement and nitric oxide synthesis. BMC Cell Biol. 2013;14:22.

35. Maeda M, Hayashi T, Mizuno N, et al. Intermittent high glucose implements stress-induced senescence in human vascular endothelial cells: role of superoxide production by NADPH oxidase. PLoS One. 2015:10:e0123169.

36. Rajamani $U$, Jialal I. Hyperglycemia induces Toll-like receptor-2 and -4 expression and activity in human microvascular retinal endothelial cells: implications for diabetic retinopathy. J Diabetes Res. 2014;2014:790902.

37. Mudaliar H, Pollock C, Ma J, et al. The role of TLR2 and 4-mediated inflammatory pathways in endothelial cells exposed to high glucose. PLoS One. 2014;9:e108844

38. Lu Z, Li Y, Jin J, et al. Toll-like receptor 4 activation in microvascular endothelial cells triggers a robust inflammatory response and cross talk with mononuclear cells via interleukin-6. Arterioscler Thromb Vasc Biol. 2012;32:1696-706.

39. Hua KF, Wang SH, Dong WC, et al. High glucose increases nitric oxide generation in lipopolysaccharide-activated macrophages by enhancing activity of protein kinase C- $\alpha / \delta$ and NF-кB. Inflamm Res. 2012;61:1107-16.

\section{Submit your next manuscript to BioMed Central and take full advantage of:}

- Convenient online submission

- Thorough peer review

- No space constraints or color figure charges

- Immediate publication on acceptance

- Inclusion in PubMed, CAS, Scopus and Google Scholar

- Research which is freely available for redistribution

Submit your manuscript at

www.biomedcentral.com/submit

C BioMed Central 